\title{
Diverticula in Male Lycorea halia Butterflies (Lepidoptera: Nymphalidae: Danaini: Itunina)-Support Organs for Everted Hairpencils with Unique Ultrastructure
}

\author{
W GnATZY ${ }^{1}$, OW FISCher ${ }^{2}$, A KIESEL $^{2}$, RI VANe-Wright ${ }^{3}$, M Boppré $^{2}$ \\ ${ }^{1}$ Institut für Ökologie, Evolution and Diversität, Goethe Universität, Frankfurt am Main, Germany \\ ${ }^{2}$ Forstzoologie und Entomologie, Albert-Ludwigs-Universität, Freiburg im Breisgau, Germany \\ ${ }^{3}$ Dept of Entomology, The Natural History Museum, London, Durrell Institute of Conservation and Ecology (DICE), and School of Anthropology \\ and Conservation, Univ of Kent, Canterbury, UK
}

\section{Keywords}

Androconial organs, functional morphology, extracellular fibril bundles, courtship

\section{Correspondence}

M Boppré, Forstzoologie und Entomologie, Albert-Ludwigs-Universität, 79085 Freiburg im Breisgau, Germany; boppre@fzi.unifreiburg.de

Edited by Roberto Romani - Univ of Perugia

Received 12 July 2019 and accepted 12 September 2019

Published online: 5December 2019

(C) The Author(s) 2019

\begin{abstract}
The involvement of the diverticula, a synapomorphy for Itunina, in protrusion and expansion of hairpencils by male Lycorea halia (Hübner, 1816) is demonstrated for the first time. They facilitate maintaining the haemolymph pressure necessary to keep the hairpencils everted. The diverticula are curved hook-like lobes, open to the body cavity and densely filled with tracheae and threads made by units of two staggered cells surrounding a central extracellular fibril bundle. Such complex structures, apparently metabolically active, have not been reported for insects previously and might indicate additional functions, but their functional role(s) remains a puzzle. When a male emerges from pupa, the diverticula are not yet formed; this happens only during the first protrusion of the hairpencils.
\end{abstract}

\section{Introduction}

Milkweed butterflies (Nymphalidae: Danainae: Danaini) of the genera Lycorea and Anetia (Itunina) share unique structures associated with the male genitalia and the androconial organs (hairpencils). Named the 'dorsal diverticulum' by Ackery and Vane-Wright (1984:27), these organs represent a pair of hook-shaped lobes, first depicted by D'Almeida (1939: plate 12,14) but without any comment. In general, males of milkweed butterflies exhibit a wide variety of specialisations associated with chemical communication (Ackery \& Vane-Wright 1984, Boppré \& Vane-Wright 1989) but nothing comparable to the diverticula. So far, diverticula have only been seen in dry-preserved butterflies from museum collections (D'Almeida 1939: plate 12, fig. 14, Ackery \& Vane-Wright 1984). Here, we report on the use of these organs by living males and their morphology and ultrastructure.

\section{Material and Methods}

Pupae of Lycorea halia (Hübner, 1816) were purchased (as L. cleobaea) from dealers; they originated from captive breeding in Belize, El Salvador and Costa Rica. Butterflies were kept in gauze cages and fed with a sugar-honey solution.

\section{Live observations}

To study the use of diverticula and hairpencils, males were mechanically irritated by holding them by their wings. Overview images and video clips of protruding and everted hairpencils were taken with a Nikon Coolpix 4500.

\section{Light microscopy}

For observing fresh diverticula and hairpencils and for dissecting abdomens, males of different age were killed in a 
deep freezer and a stereo microscope (ZEISS SteREO Discovery.V8) was employed. Images were obtained with a KEYENCE VHX-700FD digital microscope equipped with a VHZ2OR/VH-Z2OW zoom lens 20-200x and a polarisation filter OP-87429. Several abdomens were fixed with $25 \%$ glutardialdehyde: $0.1 \mathrm{M} \mathrm{Na}$ cacodylate (1:3) and stored in 70\% ethanol for later study, some were macerated in $\mathrm{KOH}$, and methylene blue was applied for getting better contrast.

\section{Scanning electron microscopy}

For scanning electron microscopy (SEM), hairpencils and diverticula were either air dried or (mostly) treated after Nation (1983), glued on aluminium stubs using adhesive carbon disks (Leit-Tab; Plano GmbH, Wetzlar, Germany), goldcoated in an Edwards Sputter Coater and studied at an accelerating voltage of $10 \mathrm{kV}$ with a ZEISS DMS $940 \mathrm{~A}$ equipped with a DISS5 unit (point electronic; Halle, Germany).

Preparations for field emission scanning electron microscopy (FeSEM) were prefixed as for transmission electron microscopy (TEM) (below). After that, the specimens were dehydrated and critical-point dried in a Polaron unit using $\mathrm{CO}_{2}$ and amyl-acetate $(2 \times 15 \mathrm{~min})$. The dried preparations were mounted with carbon disks (as above) or with minute drops of conductive carbon cement (Leit-C; Plano, Wetzlar, Germany) on aluminium stubs (as above). Finally, the specimens were coated with gold in an Edwards Sputter Coater and then examined using a Hitachi S-4500 FeSEM at an accelerating voltage of $1-5 \mathrm{kV}$.

\section{Transmission electron microscopy}

Freshly isolated diverticula were fixed at $4^{\circ} \mathrm{C}$ in a primary fixative of $2 \%$ glutardialdehyde dissolved in a rinse buffer of $0.16 \mathrm{M}$ cacodylate $(\mathrm{pH} 7.2-7.3$ ) containing $10 \%$ sucrose. After $2.5 \mathrm{~h}$, tissues were washed three times with rinse buffer before being transferred to a second fixative ( $2 \%$ osmium tetroxide dissolved in rinse buffer, w/v) for $2 \mathrm{~h}$. After thoroughly washing with rinse buffer, tissues were gradually dehydrated in a graded ethanol series $(30-100 \%$ v/v). From absolute ethanol, specimens were transferred to propylene oxide and infiltrated with mixtures of propylene oxide and Epon 812 before embedding in pure Epon resin. Ultrathin silver to golden sections $(60-80 \mathrm{~nm})$ were made using diamond knives (DuPont) on an Ultracut E ultramicrotome (ReichertJung, Wien, Austria), mounted on Pioloform-coated slot grids and double-stained with uranyl acetate and Luft's lead citrate to enhance contrast. Images were taken with a Phillips CM 12 transmission electron microscope operating at $80 \mathrm{kV}$.

\section{Documentation}

Digital images were adjusted for brightness and contrast with Adobe $^{\circledR}$ Photoshop $^{\circledR}$ CS 6 and compiled with Adobe ${ }^{\circledR}$ InDesign ${ }^{\circledR}$ CS6 on a MacBook Pro.

\section{Results}

Hairpencils and diverticula

When one catches a male Lycorea butterfly, it will instantly expand its hairpencils (see Discussion). With haemolymph pressure (as in other Danaini; Pliske \& Salpeter 1971), the hairpencil sheaths are everted like turning a finger of a glove inside out, and the hairs unfold successively. This also happens when holding a male by its wings only. Eventually, the hairs form large spheres of impressive appearance (Fig $1 \mathrm{H}$ ). Along the hairpencil tubes, a dorsal crest of long hairs is apparent-reminiscent of a mohican haircut (Fig 1G).

Two curved lobes, the diverticula, appear simultaneously with the hairpencils at the tip of the abdomen (Fig $1 A-G$ ). When hairpencil hairs are fully expanded $(F i g 1 H)$, the diverticula show up dorsally as yellowish or yellowish-brown hooks with their tips directed downwards and enclosing the bases of the hairpencil sheaths (Fig $1 \mathrm{~B}-\mathrm{H})$. As a result, the exerted diverticula bring the hairpencil sheaths laterally perpendicular to the long axis of the abdomen and support them in this position.

Hairpencil display can last for several minutes. When the insect is released, hairpencils and diverticula are withdrawn into the abdomen. Expansion can be elicited after a short pause again; however, eventually, the response decreases (habituation).

\section{Anatomy of hairpencils and diverticula}

The hairpencil hairs insert at and rest within two sheaths with retractor muscles at their bases (Fig 2A, B). The number of hairs per brush is about 1,500 , their length is ca $7 \mathrm{~mm}$ and their diameter ca $25 \mu \mathrm{m}$. The surface is evenly sculptured (Fig $11, K)$.

In a dissected abdomen, the two 3.5-mm-long diverticula, which lie dorsal to the external genitalia between the hairpencil sheaths, are very conspicuous (Fig $2 \mathrm{~A}, \mathrm{~B}$ ). The intersegmental membrane between segments VIII-IX links the diverticula with the uncus as well as the hairpencil sheaths. Thus, protrusion and retraction of both hairpencils and diverticula is made possible (see below). In relation to the haemocoel, the diverticula are open to the lumen of the abdomen with a bunch of ca 18 - $\mu \mathrm{m}$-thick threads sticking out for up to $300 \mu \mathrm{m}$ (Figs 2 and 4 ). 
Fig 1 Macrophotographs of hairpencils and diverticula in Lycorea halia: $(\mathrm{A}-\mathrm{G})$ protrusion of hairpencils (hp) and diverticula (d) by living males in different stages and views. (H) Fully expanded hairpencils, note diverticula latching onto the hairpencil stalks. (I, K) SEM of a hairpencil hair. $(A, B, E, G, H)$ Ventral, (C, D) lateral, (F) dorsal, view. $m h$ 'mohican'-like hair crest. Scale bars: $\mathrm{H} 5 \mathrm{~mm}, \mathrm{I} 10$ $\mu \mathrm{m}, \mathrm{K} 5 \mu \mathrm{m}$.
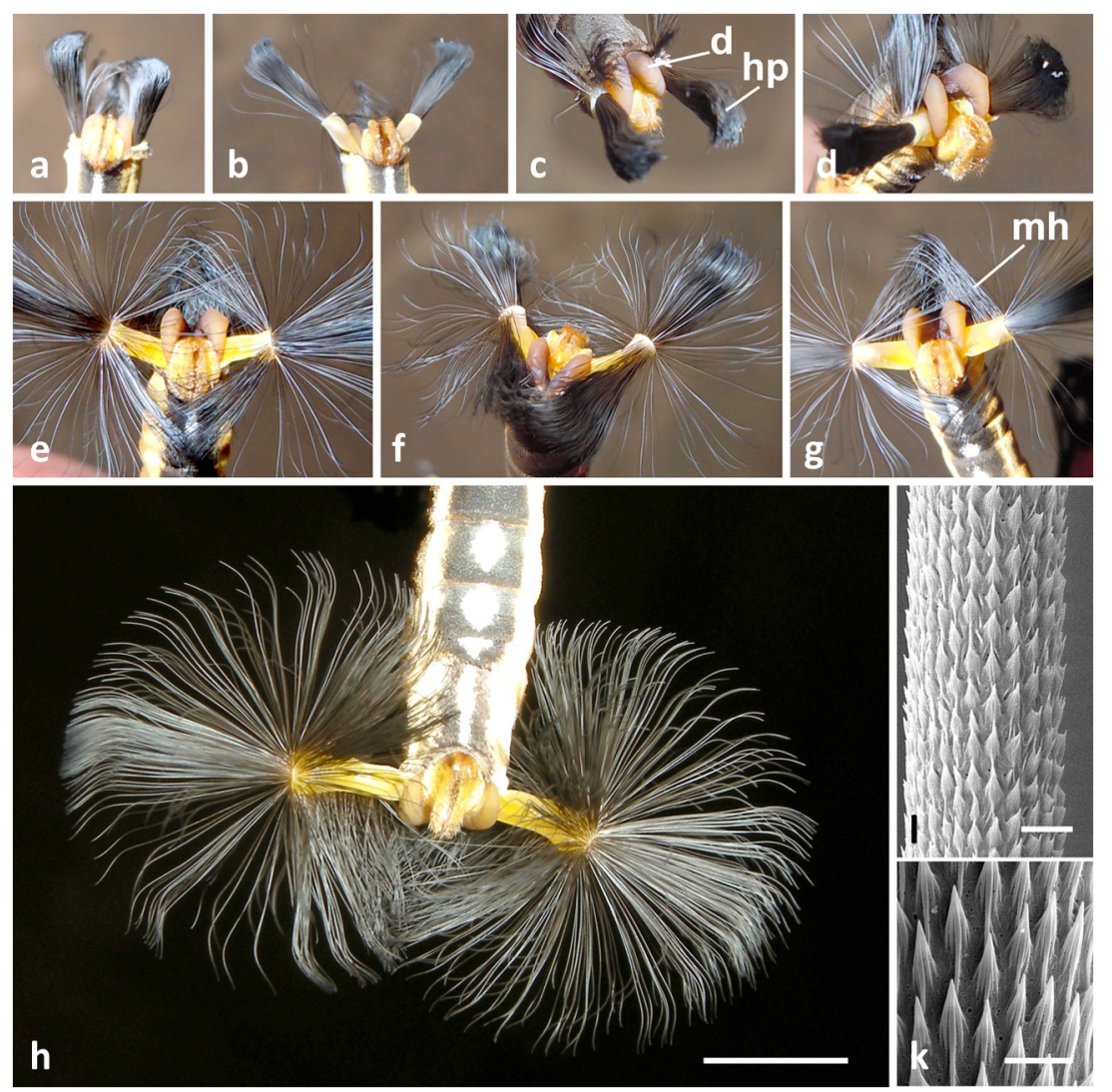

\section{Ultrastructure of diverticula}

The surface of diverticula shows a rugose appearance (Fig 3), at higher magnification, a folded, granular structure, with roughly spherical extrusions about $7 \mu \mathrm{m}$ in diameter (Fig 3D). Inside, diverticula are densely packed with the threads (Figs 2D and $4 A, B$ ), which originate at the inner wall of a diverticulum and end blindly (Fig 4B, D). They are surrounded by haemolymph and numerous tracheae and tracheoles (Figs 2 and 4 C, D).

The ultrastructure of the threads is unique. Each consists of countless units stacked in a cylindrical column, like a rouleau (Fig 5A). A thread unit is approx. $10 \times 7 \mu \mathrm{m}$ and is made up by two cells which are arranged more or less crescentshaped, lining an extracellular space in their centre (Fig 5B, $D)$. Each thread cell is separated from the haemolymph space by a prominent basal lamina (Figs $5 \mathrm{C}$ and $6 \mathrm{~A}$ ); thread units are arranged slightly staggered (Fig 5A). The apical cell membrane to the extracellular space is differentiated into short microvilli (Fig 7B). The two cells forming a unit are interconnected via zonulae adhaerentes; these cell connections exhibit septate desmosomes (Fig 6A cmp. with 5B, D).

All thread cells possess spherical, well-developed nuclei measuring about 5-6 $\mu \mathrm{m}$ with a prominent nucleolus and decondensed chromatin. Their cytoplasm houses numerous microtubules and mitochondria (Figs 5D and 6B) which are characterised by transversally oriented cristae and a dense matrix. The number of free ribosomes is remarkable (Fig 6B). A weakly developed tubular form of endoplasmic reticulum can be found throughout the cytoplasm.

All cells making a thread form an extracellular space running centrally along its longitudinal axis (Figs $5 \mathrm{C}$ and $7 A, B)$ which contains fibril bundles surrounded by a matrix of diffuse material. The fibrils show up in TEM sections (Figs $5 C, D$ and $7 A, B$ ) but also in SEM (Figs $5 B$ and 7C). Probably, the fibrils represent a continuous string throughout the entire length of the canal but this could not be verified with certainty. Each thread is anchored at the diverticulum endocuticle by its fibril bundle (Fig $7 \mathrm{~A}$ ).

\section{Formation of diverticula during adult life}

During adult life, the diverticula change their colour from fleshy white-yellow to dark brown, likely due to sclerotisation.

Dissections of males in the process of emerging from pupa which thus had never before protruded their hairpencils show a very different condition than that of older males (see above): no diverticula are visible, instead there is a large bunch of threads (Fig 8A), attached to the yet flexible intersegmental membrane VIII-IX. Treatment with $\mathrm{KOH}$ dissolves the threads but leaves 
Fig 2 Anatomy of the abdominal tip and diverticula of male Lycorea halia in dorsal view: (A, B) overviews in different viewing angles showing diverticula (d), diverticula threads (th) and tracheae (tr), hairpencils ( $h p$ ) and the intersegmental membrane VIII-IX (im); rm retractor muscle; compare with Fig 8A, B. (C) Isolated diverticula with threads sticking out, entangled by numerous tracheae. (D) Isolated diverticula slit open showing that threads and tracheae ooze out. Scale bars: $1 \mathrm{~mm}$.

Fig 3 FeSEM (A, D) and SEM (B, C) images of the surface of diverticula in Lycorea halia in increasing magnification. Scale bars: A $200 \mu \mathrm{m}, \mathrm{B} 50 \mu \mathrm{m}, \mathrm{C} 10$ $\mu \mathrm{m}$, D $2 \mu \mathrm{m}$.
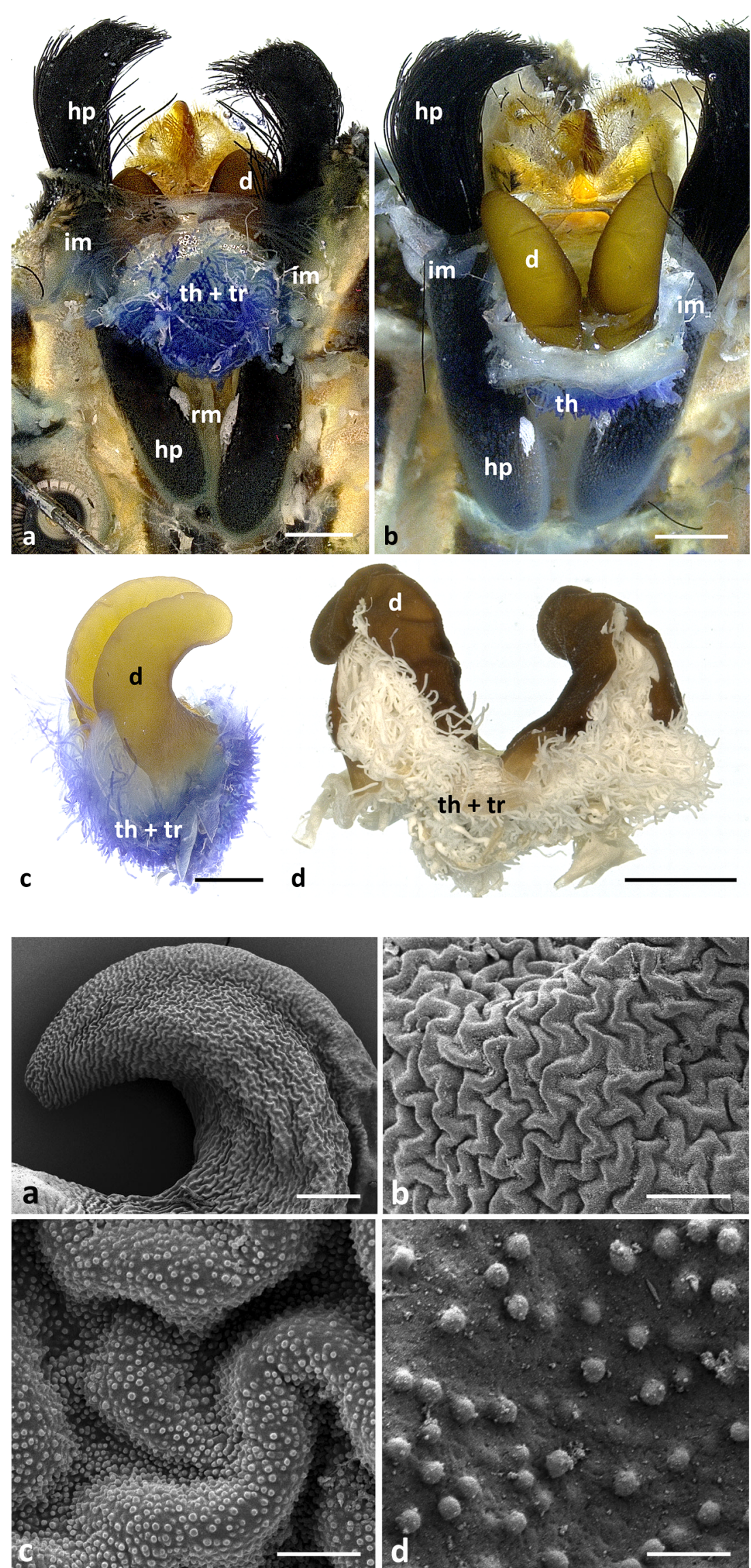
Fig 4 SEM images of diverticula threads (th) and tracheae (tr) in slit open diverticula of Lycorea halia: $(\mathrm{A}, \mathrm{B})$ threads oozing out a diverticulum. (C, D) Threads and tracheae and tracheoles. is inner surface of diverticulum where threads originate, os outer surface of diverticulum (see Fig 3), to tracheole. Scale bars: A, B $200 \mu \mathrm{m}, \mathrm{C} 40 \mu \mathrm{m}, \mathrm{D} 20 \mu \mathrm{m}$.
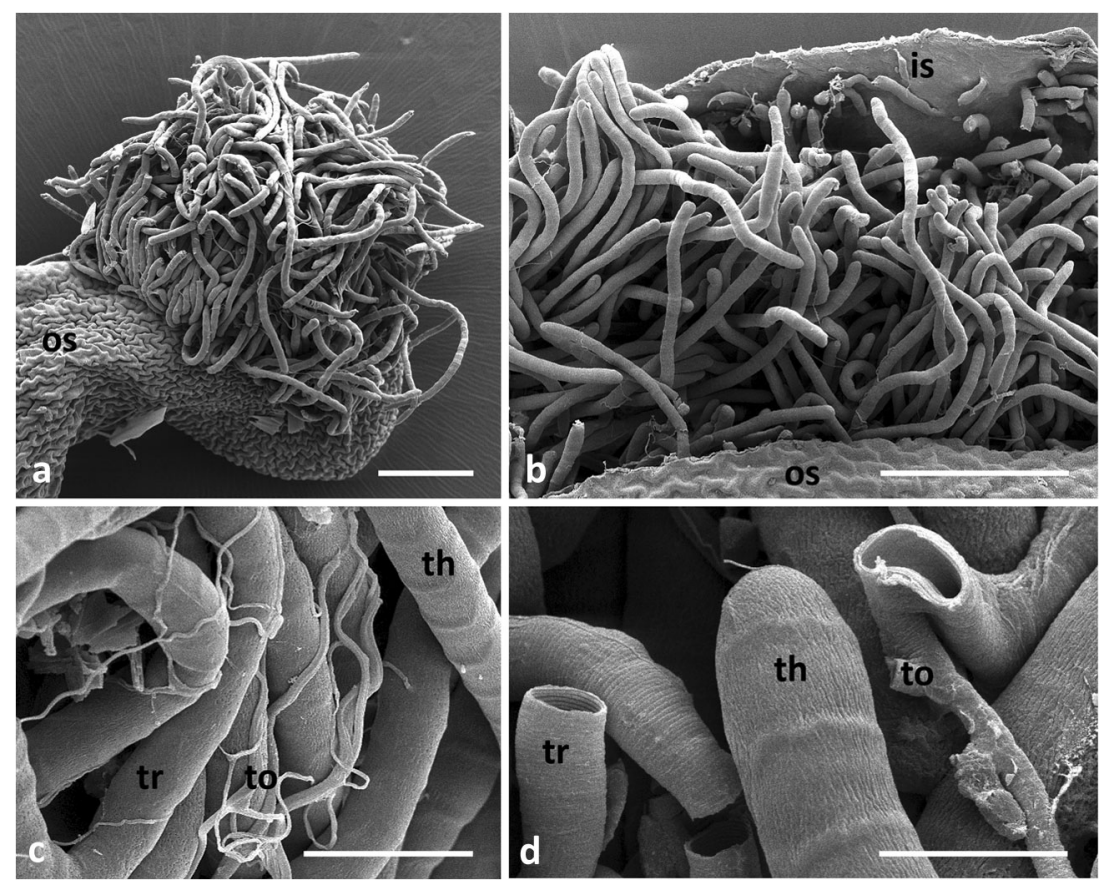

Fig 5 Ultrastructure of threads of diverticula in Lycorea halia: $(A$, B) under FeSEM, (C, D) under TEM. (A) Outer surface showing thread units, (B) cross fracture, (C) longitudinal and (D) cross section. Arrows cell boundaries, $b /$ basal lamina, $f b$ fibril bundle, $d m$ diffuse material, $m$ mitochondria, $n$ nucleus, $h s p$ haemolymph space, thc1, thc2 the two cells which form a thread unit, to tracheole. Scale bars: A, C $10 \mu \mathrm{m}, \mathrm{B}, \mathrm{D} 5 \mu \mathrm{m}$.
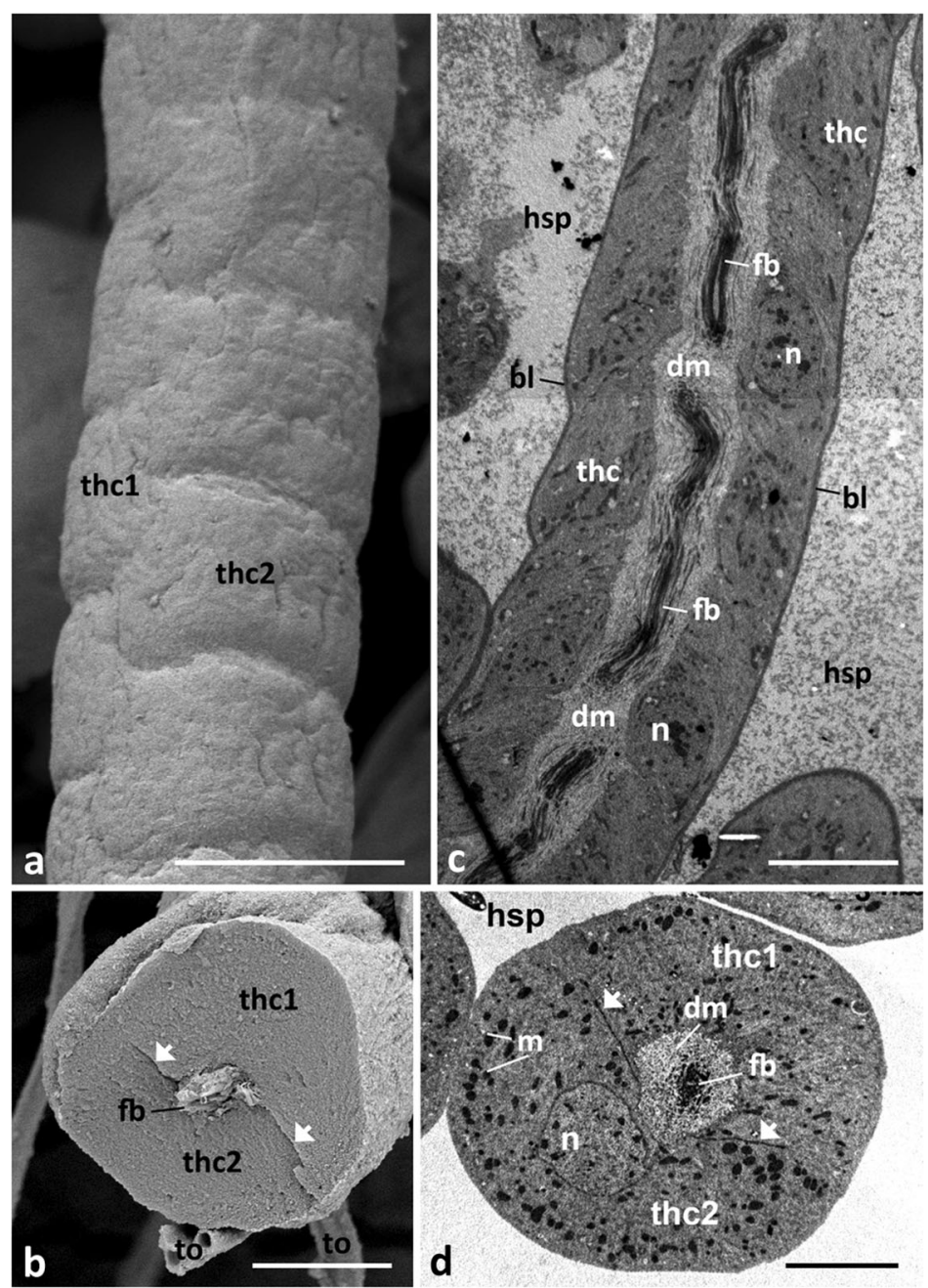
Fig 6 Cytoplasmic organisation of thread cells in male Lycorea halia: (A) TEM cross-section through a single thread showing cell boundaries between thread cells (thc1, thc2); inset microtubules (arrows) enlarged. (B) TEM longitudinal section through a thread cell. Arrow heads cell boundary with desmosomes, $b /$ basal lamina, dotted circle cross-cut microtubules, dotted square free ribosomes, $d m$ diffuse material, Ga Golgi apparatus, $h s p$ haemolymph space, $m$ mitochondria, $m t$ microtubules, $n$ nucleus. Scale bars: $A 1 \mu \mathrm{m}$, inset A $0.2 \mu \mathrm{m}, \mathrm{B} 0.5 \mu \mathrm{m}$.
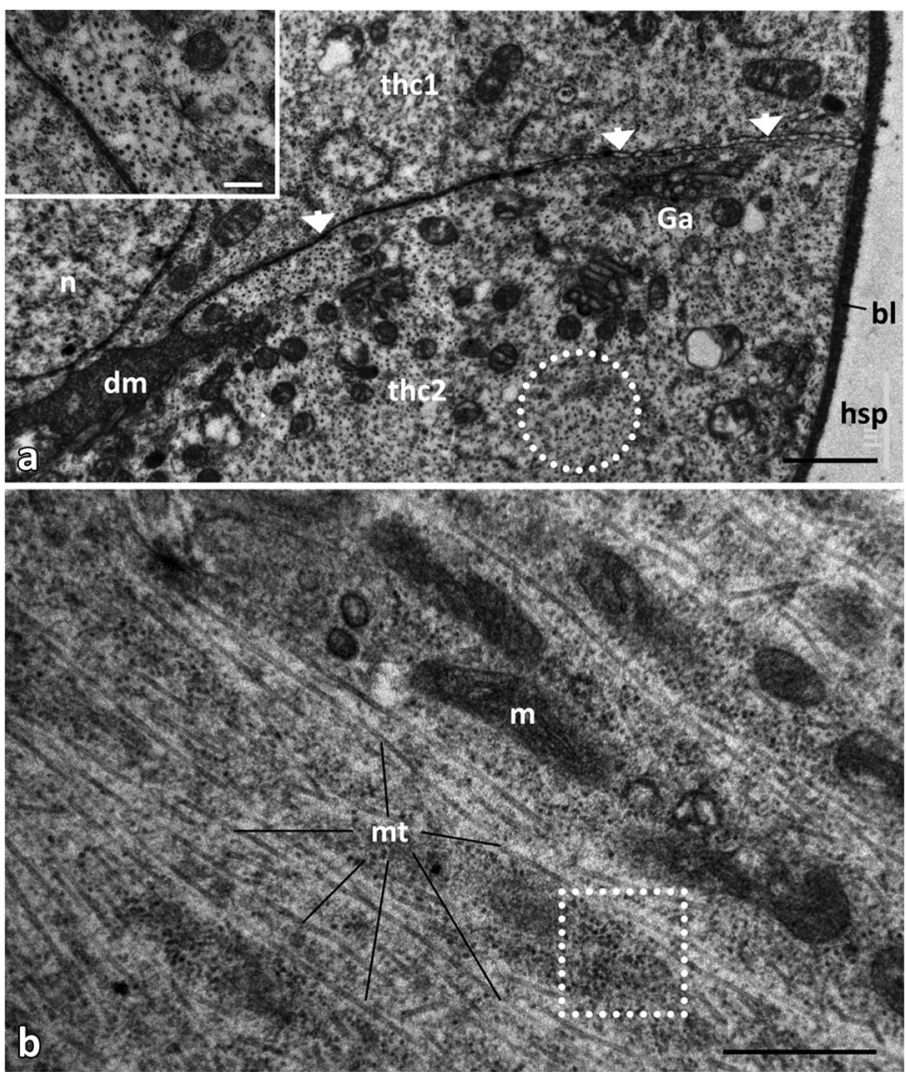

Fig 7 Details of diverticula threads of Lycorea halia: (A) anchoring of a thread (th) via its fibril bundle $(\mathrm{fb})$ in the endocuticle (en) of a diverticulum wall. (B) Fibril bundle (fb) within diffuse material $(\mathrm{dm})$ and microvilli (mv) at cell border. (C) Fibril bundle of a cross fractured thread. (A, B) longitudinal TEM sections, insets ( $A$ and $C$ ) FeSEM. Dotted circle anchoring area, $d w$ diverticulum wall, ec epidermal cell, ex exocuticle, $h s p$ haemolymph space, $m v$ microvilli, thc thread cell. Scale bars: $A$, inset $A 10 \mu \mathrm{m}, \mathrm{B}, \mathrm{C} 1 \mu \mathrm{m}$, inset $B 5 \mu \mathrm{m}$.
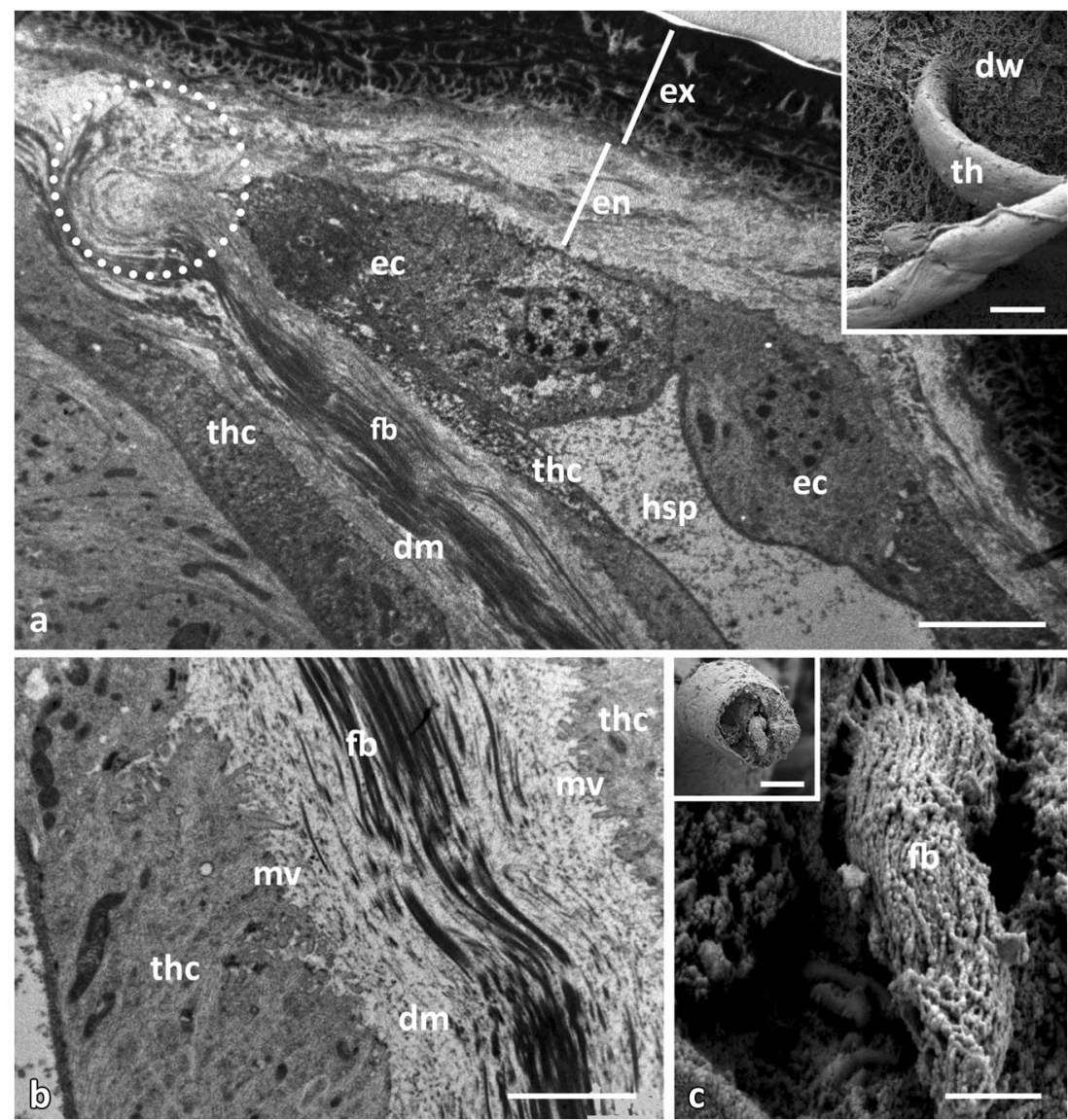
Fig 8 Anatomy of the abdominal tip of a Lycorea halia male in the state of emerging from pupa: (A) two bundles of threads (th, blue), in between many shiny tracheae (tr, white), hairpencil sheaths (hp), retractor muscles (rm) and intersegmental membrane VIIIIX (im). (B) Preparation as in A but treated with $\mathrm{KOH}$, showing intersegmental membrane of proto-diverticula (pd) without (except small residuals) threads; note the proto-diverticula are inverted; compare with Fig 2A, B. (C) Hairpencil tips plus intersegmental membrane appearing due to artificial protrusion, with diverticula not yet protruded; viewed ventrally; the asterisk marks from where they will appear, compare with Fig 1. (D, E) Intermediate state of diverticula formation. (C-E) Grabbed from video clips. (F, G) Male protruding hairpencils partially. Scale bars: $1 \mathrm{~mm}$.
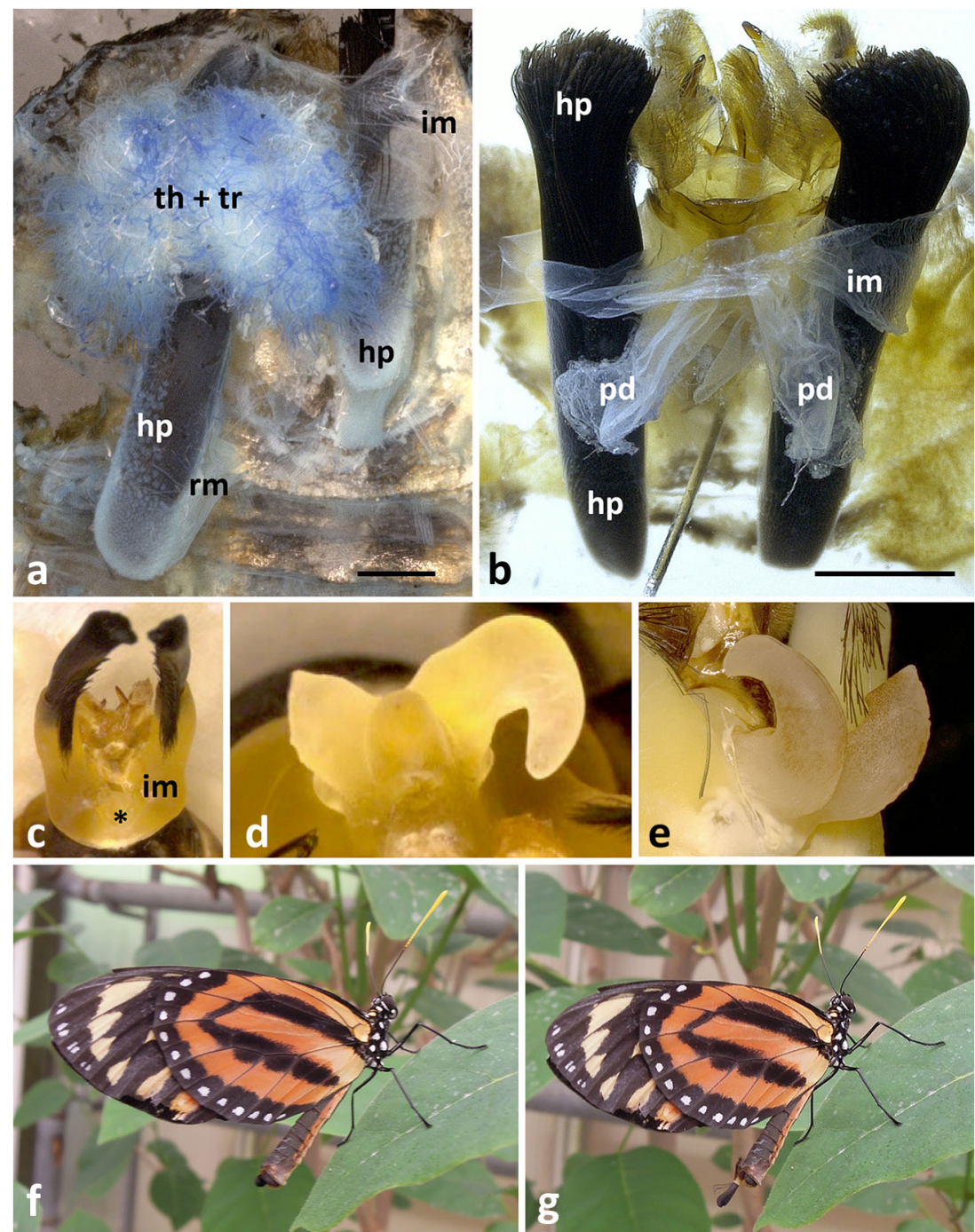

the membrane (Fig 8B). Thus, from these proto-diverticula, the diverticula are formed when the hairpencils are protruded for the first time. Indeed, when the abdomen of a newly emerged male is squeezed from front to back under a microscope, it can be seen that the diverticula appear like eversion of a finger of a glove (Fig 8D, E), similar to the hairpencils - the threads are inside. Diverticula then show up as light lobes, yet missing their final hook-like shape (Fig 8E). Thus, in an emerging male, the proto-diverticula lie within the haemocoel and via an adult behaviour (first protrusion), they are packed into sheaths (part of the intersegmental membrane); these sclerotise and henceforth retain their form as stable hooks which are protruded and retracted jointly with the hairpencils.

Figures $8 \mathrm{~F}$ and $8 \mathrm{G}$ show a male protruding its hairpencils in part, never fully, while sitting on a leaf. They are from a series of photographs taken in a butterfly house in ignorance of the unusual formation of the diverticula-perhaps, they document a male protruding the hairpencils for the first time for forming its diverticula.

\section{Discussion}

\section{Hairpencil employment in Danaini}

Courtship behaviour of milkweed butterflies involves the display of male hairpencils for dissemination of pheromones in close vicinity to a female (Brower et al 1965, Boppré 1984, Boppré \& Vane-Wright 1989). Lycorea ceres (D'Almeida 1939) is the species for which male scents have been documented and analysed for the first time in Lepidoptera (Meinwald et al 1966). As yet no field-studies on the behaviour of this taxon have been reported although collectors know that Lycorea expand their hairpencils when being handled (DeVries 1987, Meinwald et al 1966, Hernández-Baz et al 2019), and DeVries 
(1987:213) stated: 'Males perch during the morning in the sub-canopy ... occasionally with the hair pencils extruded'.

Courtship in Danaini has rarely been analysed in detail. The study by Brower et al (1965) on the queen butterfly, Danaus gilippus (Cramer 1776), remains the most complete, while the one by Pliske (1975) deals with Danaus plexippus (Linnaeus 1758) which is not representative with respect to courtship in Danaini (Boppré 1993, Brower et al 2007). The hairpencils of many Danaini disseminate pheromonetransfer-particles (PTPs; Boppré \& Vane-Wright 1989) during courtship and are expanded only briefly (maximally for some seconds) close to a female's antennae. On the contrary, Euploea species, none of which employs PTPs, have been seen with expanded hairpencils not only when hovering above a female but also when flying in 'courtship mood' with no female in their vicinity (Latter \& Eltringham 1935, Sevastopulo 1944, Hardy 1951), then disseminating pheromones, perhaps, to attract a female, to repel other males or to mark a territory? On the courtship of Lycorea, relatively rarely encountered forest butterflies, we can only guess. For several reasons, we assume it is similar to Euploea: DeVries (1987) saw males flying with expanded hairpencils; both taxa expand their organs voluntarily when mechanically stimulated (perhaps to startle predators upon attack); Lycorea and Euploea are also quite close with respect to their larval hostplants being the only danaine genera using species of Moraceae (Ficus spp.) (Ackery \& Vane-Wright 1984, cf. Boppré et al 2020). Unfortunately, we had the experience that Lycorea do not court and mate in flight cages as, e.g. Euploea do (Boppré et al unpubl.). Our finding that the diverticula are voluntarily protruded together with the hairpencils (which has not been observed before) and latch at the bases of the hairpencil stalks suggests that the diverticula are support organs which facilitate maintaining the haemolymph pressure necessary to keep the hairpencils everted. Perhaps, Lycorea fly for longer periods and/or more often with their hairpencils expanded than Euploea?

\section{Ultrastructural and developmental peculiarities of diverticula}

As supporting organs for expanded hairpencils during courtship activities, simple cuticular hooks would do. However, the architecture of the diverticula is most complex, exhibiting unexpected ultrastructural details and the organs appear to be metabolically active. Perhaps, their primary function is all but a hook-but if so, what other function could this extraordinary organ have? It may be significant that the related genus Anetia has what appears to be comparable paired structures that are much smaller and would not seem capable of providing a similar mechanical function.

Other Danaini in addition to hairpencils possess alar androconial organs with which mechanical contacts of the hairpencils are established behaviourally independent of courtship activities (Boppré \& Vane-Wright 1989). Lycorea are devoid of alar organs-do diverticula contribute to the pheromones released by the hairpencils or to their biosynthesis? Then, however, intimate mechanical contact between diverticula and hairpencil hairs would be essential.

The surprising finding that diverticula achieve their final shape during their first protrusion by the adult male, adds to the puzzle. Or can this shed light onto the mystery and present the key for understanding diverticula fully? Perhaps, the unique threads primarily fulfil an important function during the pupal stage? However, to the best of our knowledge, such extracellular cell-shielded fibril bundles have never been described before-but we lack any idea regarding their functional role.

In any case, circumstancial evidence suggests that the diverticular threads are metabolically active: they are in connection with the haemolymph and the tracheal system, thread cells possess large nuclei, many mitochondria and numerous ribosomes. If only a physiological rôle could be recognised.

The biology of milkweed butterflies is less understood than one might assume in view of the huge amount of literature on this taxon (see Boppré et al 2019), and our paper adds another dimension, namely usually invisible internal structural peculiarities.

Acknowledgements We are grateful to Olaf Dittberner $(\dagger)$ and Marion Stöhr for skilful technical assistance, and to Manfred Ruppel for excellent assistance with the FeSEM. Eva Schottmüller but also Andrea Andris, Hannes Freitag and Monika Siegel are cordially thanked for well-maintenance of MB's greenhouse facilities and plant and insect cultures. RIV-W gratefully acknowledges support from The Leverhulme Trust emeritus programme.

Authors' Contribution Statement WG concentrated on the ultrastructure, OWF and AK did most of the preparations and studied the organs macroscopically and with SEM, MB and RIV-W initiated and overviewed the project and drafted the manuscript.

Open Access This article is distributed under the terms of the Creative Commons Attribution 4.0 International License (http://creativecommons.org/licenses/by/4.o/), which permits unrestricted use, distribution, and reproduction in any medium, provided you give appropriate credit to the original author(s) and the source, provide a link to the Creative Commons license, and indicate if changes were made.

\section{References}

Ackery PR, Vane-Wright RI (1984) Milkweed butterflies: their cladistics and biology. British Museum (Natural History), London

Boppré M (1984) Chemically mediated interactions between butterflies. Symp R Ent Soc 11:259-275 (= Vane-Wright RI, Ackery PR (eds) The biology of butterflies, Academic Press; reprinted 1989 by Princeton University Press)

Boppré M (1993) The American monarch: courtship and chemical communication of a peculiar danaine butterfly. In: Malcolm SB, Zalucki MP 
(eds) Biology and conservation of the monarch butterfly. Natural History Museum of Los Angeles County, Los Angeles, pp 29-41

Boppré M, Vane-Wright RI (1989) Androconial systems in Danainae (Lepidoptera): functional morphology of Amauris, Danaus, Tirumala and Euploea. Zool J Linnean Soc 97:101-133

Boppré M, Petschenka G, Vane-Wright RI (2020) Cardenolides vs pyrrolizidine alkaloids and stickiness vs toxicity - a hypothesis on the evolution of hostplant relationships in milkweed butterflies (Lepidoptera: Nymphalidae: Danainae: Danaini). Manuscript

Brower LP, Brower JVZ, Cranston FP (1965) Courtship behavior of the queen butterfly, Danaus gilippus berenice (Cramer). Zoologica 50:139

Brower LP, Oberhauser KS, Boppré M, Brower AVZ, Vane-Wright RI (2007) Monarch sex: ancient rites, or recent wrongs? Antenna 31: 12-18

D'Almeida RF (1939) Revisão das especies americanas da superfamilia Danaoidea (Lepid.: Pieridae). Parte 1 - Familia Danaidae, subfam. Danainae. Mem Inst Oswaldo Cruz 34:1-113 + 30 plates

DeVries PJ (1987) The butterflies of Costa Rica and their natural history. Papilionidae, Pieridae, Nymphalidae. Princeton University Press, Princeton

Hardy GH (1951) The courtship of Euploea corinna Macleay (Lep., Danaidae). Entomol Mon Mag 87:8-9
Hernández-Baz F, Castañeda-Ortega JC, Lara-Capistrán L, NúñezCamargo MDC, González JM (2019) Protrusion of the androconial organs of Lycorea halia atergatis Doubleday [1847] (Nymphalidae) from a cloud forest at Veracruz State, México. Southwest Entomol 44:327-330

Latter OH, Eltringham H (1935) The epigamic behaviour of Euploea (Crastia) core asela (Moore) (Lepidoptera Danainae). Proc R Soc Lond B117:470-482

Meinwald J, Meinwald YC, Wheeler JW, Eisner T, Brower LP (1966) Major components in the exocrine secretion of a male butterfly (Lycorea). Science 151:583-585

Nation JL (1983) A new method using hexamethyldisilazan for preparation of soft insect tissues for scanning electron microscopy. Stain Technol 58:347-351

Pliske TE (1975) Courtship behavior of the monarch butterfly, Danaus plexippus L. Ann Entomol Soc Am 68:143-151

Pliske TE, Salpeter MM (1971) The structure and development of the hairpencil glands in males of the queen butterfly, Danaus gilippus berenice. J Morphol 134:215-241

Sevastopulo DG (1944) Note on the courtship of Euploea core core Cr. (Lep Danaidae). Proc R Ent Soc Lond A19:10-12

Publisher's Note Springer Nature remains neutral with regard to jurisdictional claims in published maps and institutional affiliations. 